\title{
Breast Sonography - 2D, 3D, 4D Ultrasound or Elastography?
}

\author{
Christian Weismann Christian Mayr Heike Egger Alena Auer \\ Diagnostic and Interventional Breast Department, Private University Institute of Radiology, PMU, General Hospital Salzburg, Austria
}

\section{Keywords}

Breast - Ultrasound - Three-dimensional imaging . Elastography · Breast Diseases

\section{Summary}

The aim of this publication is to give an answer to the question whether $2 \mathrm{D}, 3 \mathrm{D}$ and $4 \mathrm{D}$ sonography of the breast can be replaced by elastography or whether elastography is an adjunct tool to B-mode imaging. The Breast Imaging and Reporting Data System (BI-RADS) ultrasound (US) descriptors of a lesion besides vascularity are based on B-mode imaging. US elastography displays the mechanical tissue properties. This information can be obtained by freehand compression and decompression. Acoustic radiation force impulse imaging (ARFI) produces stress with lowfrequency push pulses. Manual compression by the transducer is not necessary. Shear wave elastography (SWE) is the combination of ARFI and the measurement of the consecutive shear wave propagations in the tissue. A quantification of the elasticity in kilopascal $(\mathrm{kPa})$ is offered. Discussing B-mode imaging and elastography combined with the literature, elastography is seen as an addition to B-mode imaging with the potential to increase the specificity of the B-mode imaging-based BI-RADS assessment. In spite of additional elasticity information, the sensitivity remains high. A time-saving diagnostic algorithm for 2D, 3D US and elastography is described. In conclusion, it must be said that elasticity is not a stand-alone US modality able to replace 2D and 3D sonography.

\section{Introduction}

Modern two-dimensional (2D), three-dimensional (3D) and four-dimensional (4D) ultrasound (US) technologies offer a wide range of different access options to study breast lesions. Color Doppler US has proven to be helpful in differentiating

\author{
Schlüsselwörter \\ Brust - Ultraschall · Multidimensionaler Ultraschall . \\ Elastographie · Brusterkrankungen
}

\section{Zusammenfassung}

Diese Publikation versucht die Frage zu beantworten, ob Elastographie den 2D-, 3D- und 4D-Ultraschall der Brust ersetzen kann oder ob die Elastographie als Zusatztechnik zur B-Mode-Bildgebung zum Einsatz kommt. Abgesehen von der Durchblutungsstudie eines Herdes basiert die Breast Imaging and Reporting Data System (BI-RADS)-Kriterienanalyse auf dem B-Mode. Sonoelastographie stellt die mechanischen Gewebeeigenschaften dar. Diese Information kann man durch Freihandkompression und Dekompression erhalten. Acoustic Radiation Force Impulse Imaging (ARFI) steigert den Druck auf das Gewebe durch Einstrahlung eines Push-Pulses mit niedriger Frequenz. Eine manuelle Kompression mit dem Schallkopf ist dafür nicht erforderlich. Scherwellenelastographie (SWE) funktioniert auf der Basis von ARFI und den daraus resultierenden Scherwellengeschwindigkeitsmessungen im Gewebe. Die Quantifizierung der Gewebeelastizität wird in Kilopascal ( $\mathrm{kPa}$ ) angegeben. In Zusammenschau mit der Literatur ist die Elastographie als Zusatztechnik zur B-Mode-Bildgebung zu bewerten, wobei sie das Potenzial hat, die Spezifität des BI-RADS-Assessments zu steigern. Trotz zusätzlicher Elastographie bleibt die Sensitivität hoch. Ein zeitsparender diagnostischer Algorithmus von 2D- und 3D-Ultraschall mit zusätzlichem Einsatz der Elastographie wird vorgestellt. Abschließend ist zu sagen, dass die Elastographie die 2D- und 3D-Sonographie nicht ersetzt.

benign from malignant breast masses. The latest technical development to analyze a breast lesion is based on elastography. Shortages of investigation time and high examination rates cause a tension between technical progress, economical aspects, and everyday practice. The question arises whether we need the whole number of US modalities of $2 \mathrm{D}, 3 \mathrm{D}, 4 \mathrm{D}$

\section{KARGER}

Fax +497614520714

Information@Karger.de

www.karger.com

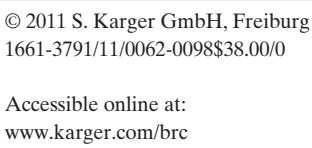

Dr. Christian Weismann

Abteilung $\mathrm{f}$. Mammadiagnostik und Mammaintervention

am Univ. Inst. f. Radiologie, LKH-Salzburg

Müllner Hauptstraße 48, 5020 Salzburg, Austria

Tel. +43 662 4482-57771, Fax -3964

christian.weismann@inode.at 
imaging and elastography or whether we can replace greyscale imaging by using only elastography or vice versa. First, the different features of B-mode imaging and the different techniques of elastography are presented to create the basis for discussing the question above.

\section{B-Mode Imaging}

B-mode imaging is related to impedance differences in the tissue and offers grey-scale information of different tissue components. 2D, 3D and 4D studies can be performed by this technique. Progress in 2D high-frequency US transducer technology in combination with compound imaging and speckle reduction is the basis for high-quality $3 \mathrm{D}$ volume US $[1,2]$. Modern breast US systems with broad-band high-frequency transducers, e.g. 6-16 MHz with full digital data management and high resolution combined with transmitter and receiver focusing, offer a high multidimensional imaging level. 4D US gives real-time 3D-rendered image information. In addition to conventional 2D sonography, 3D US provides new diagnostic information such as the ability to study a breast mass and the surrounding tissue in 3 orthogonal planes. The US Breast Imaging and Reporting Data System (BI-RADS) published by the American College of Radiology [3] and the US BI-RADS-analog version of the German, Austrian, and Swiss US Societies (DEGUM, OEGUM, SGUM) [4] are mainly based on morphological criteria discussing lesion shape, orientation, margin, lesion boundary, echo pattern, and posterior acoustic features. The growth pattern analysis of a breast lesion in the coronal plane (offered by 3D US) is implemented in the US BI-RADS-analog version. The different BI-RADS descriptors have the aim first to assess and then to classify the US-visible lesion.

Using a precise 2D US examination technique (meanderlike scanning, radial or anti-radial scanning) with overlapping scans, moderate breast tissue compression and holding the scanner perpendicular to the skin surface is the basis for detecting small non-palpable breast lesions, complementarily to mammography or used as a first-line imaging tool [5-9]. Compound imaging is able to reduce numerous shadowing artifacts in the normal breast. Automated tissue optimization and tissue-harmonic imaging [10] help to present anatomy and pathology with enhanced contrast in order to optimize the image quality.

Lesion detection with 2D US is followed by the acquisition of a static 3D volume US dataset of the lesion and the surrounding tissue, in order to assess the breast lesion related to the US BI-RADS descriptors. The static 3D US information is presented in the multiplanar display mode. In the A- or Bplane of this mode (both planes are accessible to $2 \mathrm{D}$ scanning), the lesion will be rotated around the y-axis. Compared with $2 \mathrm{D}$ imaging, a static 3D US volume offers more information, e.g. the additional coronal view, and is suitable for double reading. In the coronal plane, the lesion is analyzed for signs of compression or star/retraction pattern [11-13].

If the contrast between lesion and surrounding breast tissue is poor, 3D static volume contrast imaging (VCI) (GE Healthcare Austria GmbH, Zipf, Austria) enhances the contrast, with the aim to optimize the contours for making accurate BI-RADS assessment with correct differential criteria analysis. Static VCI provides a static 3D dataset with preselected slice thickness in all 3 planes and in different rendering modes. The surface rendering mode supports the assessment of inner cyst wall structures, e.g. a papilloma or an intraductal tumor outlined by echo-poor fluid. Echo-poor breast lesions can be rendered by inversion-mode technology. The volume of interest (VOI) has to cover the entire lesion. The inversion rendering mode presents the lesion in a $50 \%$ mixed surface smooth and $50 \%$ gradient light algorithm as a white-colored 3D model. It offers quick access to the 3D shape of an echo-poor lesion.

A $3 \mathrm{D}$ volume dataset displayed in a multiplanar view is the perfect basis to measure the long axes distances in all 3 perpendicular planes. No lesion measurement failure that may be obtained by $2 \mathrm{D}$ cross-sectional measurements can influence the results. Afterwards, the volume of the lesion is calculated by VoCal [11, 13-15]. For follow-up investigations, the long axes measurements and the volume measurement in milliliter (ml) are available. The most comprehensive documentation of a lesion can be performed with tomographic US imaging (TUI) (fig. 1). It is based on a 3D volume dataset. A topogram shows the position of the slices obtained from the $3 \mathrm{D}$ dataset. The distance between the different slices is adjusted to the lesion size in order to cover the entire lesion.

4D US means to study movements of three-dimensionally displayed objects. Movement in the breast may originate from compression and decompression of breast tissue and the lesion to analyze lesion elasticity and lesion movability, or may come from transducer movements comparable with 2D US scanning.

The panoramic scan technique is based on 2D B-mode imaging, which can be used for a precise documentation of a lesion in the breast with 1 image $[16,17]$. In the radial scan direction (duct parallel), the shortest distance between the lesion and the nipple (lesion-nipple distance) will be measured, followed by the shortest-distance measurement between lesion and skin (lesion-skin distance). The breast pictogram tells whether it is the right or the left breast. The position of the radial transducer path towards the lesion is documented by the transducer icon in the breast pictogram, using the clock for description.

\section{Elastography}

The background for implementing elastography into the daily diagnostic US practice is given by the fact that malignancies have the tendency to harden the breast tissue. Elastography 
Fig. 1. TUI documentation with the topogram and the following cross-sections of a nonHodgkin's lymphoma of the breast.

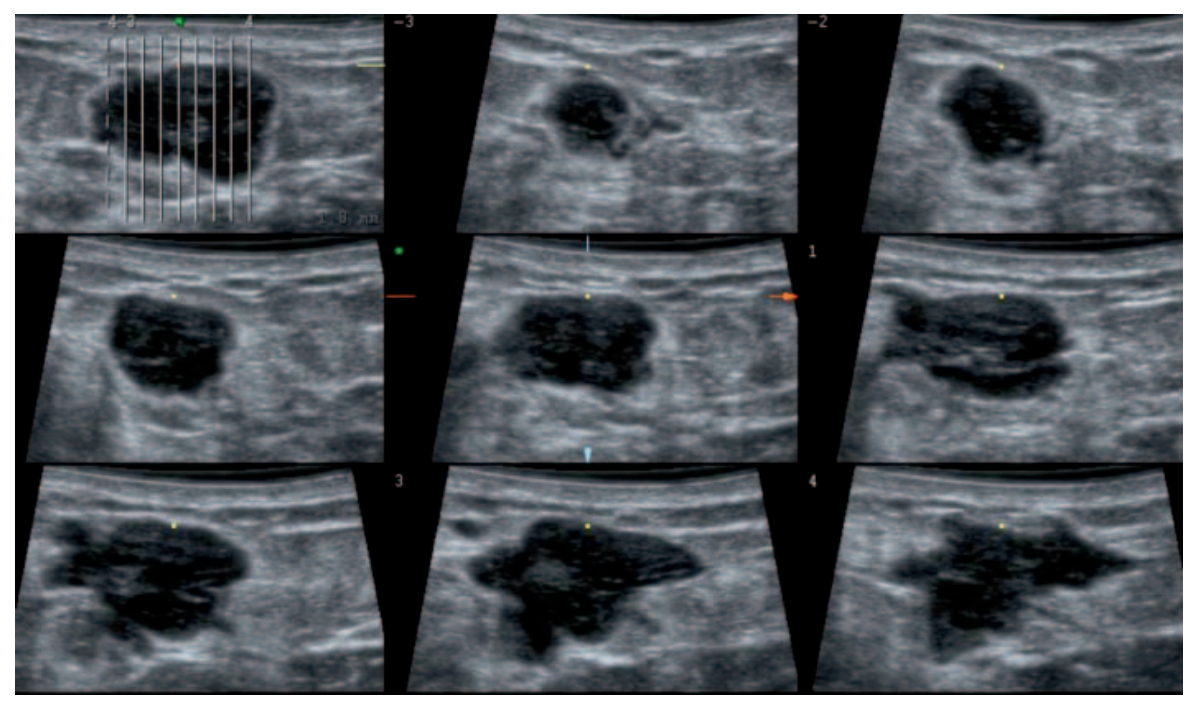

uses US to describe and to measure different degrees of stiffness in different tissues. In general, this technique is based on a 3-step method: Firstly, low-frequency vibration produces stress. Secondly, the strain in the tissue following the stress is presented on the monitor (typically in different colors related to the stiffness), and thirdly, parameters to describe the tissue stiffness are established. The freehand compression and decompression technique [18] is widely used in different US systems to produce stress in the tissue. The longitudinal strain is calculated and displayed in a superimposed color map with different colors for soft and hard tissue. The manual compression of the skin may additionally overlap with a lateral scanner slip that influences the elastography result [19]. As a consequence of this, the tissue compression is investigator dependent. Strong pressure influences the elasticity image. 4D-VCI studies work with freehand compression and decompression and offer the elasticity information in a defined slice thickness volume, with the aim to study the elastic properties of the lesion and the surrounding breast tissue within the entire slice. A developmental step towards less investigator dependency is based on the acoustic radiation force impulse imaging (ARFI) technique. The low frequency generated by the transducer produces push pulses stressing the tissue without freehand compression. The consecutive strain will be displayed on the monitor (Virtual Touch Tissue Imaging ${ }^{\mathrm{TM}}$, ACUSON, Siemens AG Healthcare, Erlangen, Germany).

The most standardized elastography technique measures the speed of waves propagating perpendicularly to the focused push pulses (= shear waves) generated by ARFI. The ShearWave ${ }^{\mathrm{TM}}$ elastography (SuperSonic Imagine, S.A., Aix-en-Provence, France) shows local elastic information and, in addition, offers a quantitative evaluation of tissue stiffness in kilopascal $(\mathrm{kPa})$ [20]. The propagation speed of the shear waves is proportional to the tissue stiffness and can be measured in meter per second $(\mathrm{m} / \mathrm{s})$ and displayed as color map (fig. 2). The commercially available ShearWave ${ }^{\mathrm{TM}}$

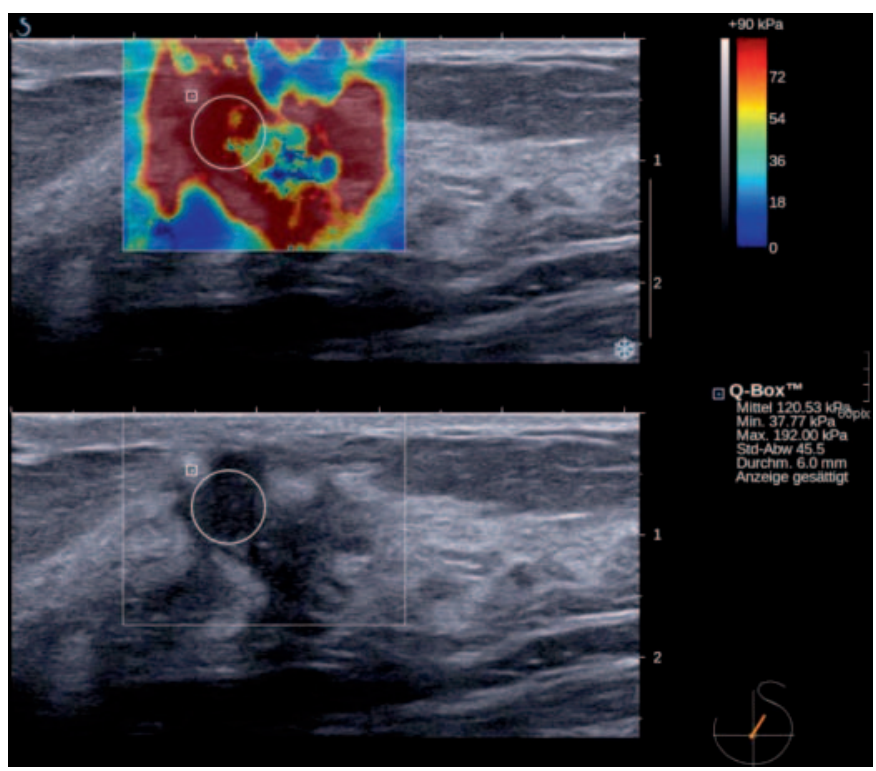

Fig. 2. SWE of an invasive ductal breast cancer with skin infiltration; the white circle within the rectangular region of interest indicates the area of quantitative elasticity evaluation in $\mathrm{kPa}$; the rectangular color map area describes the entire region tested for shear wave elasticity.

elastography is a new technology; therefore, mainly preliminary clinical results are currently available [21, 22].

\section{Discussion}

BI-RADS assessment of breast lesions is mainly based on US morphology. The BI-RADS descriptors are presented by B-mode grey-scale imaging, and the resulting BI-RADS score is predominantly influenced by B-mode information. Vascularity usually is displayed as a function of color Doppler US [23-29]. It is an additional feature in BI-RADS assessment $[3,4]$. Recent publications investigate the question 
whether elastography is able to enhance the true-positive and the true-negative results of breast lesions in addition to Bmode imaging. In most of the publications, elasticity is not studied as a stand-alone feature. It is used as a complementary technology to B-mode imaging $[22,30]$. Based on the literature, the sensitivity of B-mode breast US varies from $57 \%$ to $97 \%$ and the specificity from $60 \%$ to $90 \%$. This means that many factors are influencing the result. These factors are: education and experience of the investigator, the quality of the US equipment, and breast volume and structure. Education, experience, and technical equipment can be improved by teaching and using modern US systems. A state-of-the-art breast US unit combined with experienced investigators offers high sensitivity of $97 \%$, specificity of $82 \%$, a positive predictive value (ppv) of $71 \%$, and a negative predictive value (npv) of 78\% [30]. To analyze breast lesions with B-mode imaging means to collect mosaic stones and to put them together as a basis for the decision on BI-RADS 2 or 3 , which means that no needle biopsy is necessary, or BI-RADS 4 or 5 , with the typical consequence of core needle or vacuum aspiration biopsies [31-36]. Stavros et al. [31] evaluated different features of B-mode imaging that are indicative of a benign or malignant lesion. Beside the features of angular margins (sensitivity $83 \%$, specificity 92\%), microlobulation (sensitivity $75 \%$, specificity $84 \%$ ), and hypoechogenicity (sensitivity $69 \%$, specificity $90 \%$ ), all other lesion characteristics indicating a malignant lesion (spiculation, orientation, posterior shadowing, branch pattern, calcifications, duct extension) presented a sensitivity below $50 \%$. Combinations of different characteristics that are implemented in the BI-RADS assessment are the basis of high sensitivity and acceptable specificity [35-37]. Concerning the interobserver variability $[38,39]$ of B-mode lesion characteristics, Lazarus et al. [38] reported substantial agreement for lesion shape, boundary and orientation, moderate agreement for the margin and the posterior acoustic features, and only poor agreement for the echo pattern. These interobserver studies may give an explanation for the higher number of false-positive results in B-mode imaging with a lower specificity compared to sensitivity.

The 3D US morphology [12-15, 36, 40, 41] of a breast lesion offers, in addition to the 2D US results, the coronal plane growth pattern information as a new mosaic stone. In the coronal plane, using the retraction/star pattern sign as an indicator for malignancy and the compression pattern sign for benignancy, a sensitivity of $91 \%$ is reported by Rotten et al. $[40,41]$, a specificity of $94 \%$, a ppv of $87 \%$, and an npv of $96 \%$. In daily routine diagnostic work, 4D grey-scale US did not prove to enhance true-positive results or to reduce falsepositive results. Elasticity information obtained by 4D-VCI studies based on freehand compression and decompression were of academic interest, but have not been integrated into the routine diagnostic workflow.

The statistical data of freehand elastography with compression and decompression are related to a scoring system pub- lished by Itoh et al. [19]. A score of 1 indicates even strain for the lesion and the surrounding tissue, a score of 2 means strain in the lesion, a score of 3 shows strain in the periphery of the lesion but no strain in the lesion center, a score of 4 is characterized by a lesion without strain, and a score of 5 indicates no strain in the lesion and in the surrounding tissue or in the surrounding tissue. Using scores 1-3 for benign and scores 4 and 5 for malignant lesions, elasticity showed a sensitivity of $87 \%$ and a specificity of $90 \%$. In the publication of Hatzung et al. [30], the same score system was applied, but they found the highest sensitivity for elastography using scores 1 and 2 for benign and scores 3-5 for malignant lesions. The sensitivity was $71 \%$, the specificity $48 \%$, the ppv $39 \%$, and the npv $78 \%$. In the combination of BI-RADS descriptors and elastography, the sensitivity went up to $100 \%$ but the specificity dropped to 38\% (ppv 39\%, npv 100\%). The observed different results obtained with comparable technologies may come from the investigator dependency of the elastography method.

This means that different tissue compression by different investigators with more or less strong pressure influences the elasticity image and the consecutive score. The position of a lesion (superficial or close to the chest wall in a voluminous breast) may also influence the elasticity result. The freehand technique does not offer an objective parameter to quantify the strain. The interobserver variability resulting from interpreting the same elastography images by 3 different readers is highlighted by Burnside et al. [42]. A significant interobserver variability was reported. For all 3 readers, the area under the receiver operating characteristic (ROC) curve was greater after B-mode image analysis and strain imaging compared to B-mode imaging alone. 2 readers had a significantly higher area under the ROC curve compared with the 3rd reader.

SWE with supersonic shear imaging on the one hand provides a color map presenting the shear wave propagation speed in meter per second $(\mathrm{m} / \mathrm{s})$. On the other hand, this technique offers an objective parameter $(\mathrm{kPa})$ to quantify the tissue elasticity. Cysts with echogenic material (complicated cysts) can be differentiated from solid lesions because of their missing shear wave propagation [22]. Athanasiou et al. [22] published a BI-RADS B-mode imaging specificity of solid breast lesions of $63 \%$. Combining the quantitative SWE with the BI-RADS evaluation, the overall specificity increased up to $96 \%$. This means that, in this study, $46 \%$ of the BI-RADS 4 lesions could be down-staged to BI-RADS 3 by applying SWE. The B-mode imaging sensitivity without SWE was $96 \%$, and combined $95 \%$. At the Radiological Society of North America meeting 2010 (RSNA 2010), Cosgrove and colleagues presented data of a multicenter study on SWE with 1000 cases and an improvement of $20 \%$ on specificity compared with the BI-RADS classification alone. They showed an almost perfect agreement of the lesion size on SWE ( $\kappa=$ $0.95)$ and elasticity $(\kappa=0.91)$ calculated on 3 consecutive acquisitions. The area under the ROC curve for the BI-RADS assessment alone was 0.72 . Adding SWE information to BI- 
Table 1.2D and 3D US combined with elastography: 8 steps presenting the modified diagnostic algorithm related to imaging technology and lesion analysis

\begin{tabular}{|c|c|c|}
\hline & Imaging and analysis target & US technology \\
\hline Step 1 & lesion detection & 2D US \\
\hline Step 2 & $\begin{array}{l}\text { multidimensional lesion analysis (shape, orientation, margin, lesion boundary, } \\
\text { echo pattern, posterior acoustic features, coronal plane pattern, calcifications) }\end{array}$ & 3D US dataset \\
\hline Step 3 & lesion measurements and lesion volume calculation & 3D US dataset of step 2 \\
\hline Step 4 & documentation of the lesion with TUI or multiplanar display mode & $3 \mathrm{D}$ US dataset of step 2 \\
\hline Step 5 & vascular study of the lesion and surrounding tissue & $2 \mathrm{D}$ or $3 \mathrm{D}$ US color dataset \\
\hline Step 7 & lesion elasticity - analysis and documentation & US elastography \\
\hline Step 8 & documentation of the lesion within the breast & 2D panoramic scan \\
\hline
\end{tabular}

RADS, the area under the ROC curve increased up to 0.89 . They concluded that SWE is a reproducible technique that improves the US accuracy and is able to reduce unnecessary biopsies. Evans and colleagues, also at the RSNA 2010, presented a study of quantitative SWE focused on the cut-off value $(\mathrm{kPa})$ between benign and malignant lesions. They selected the 50-kPa value to differentiate between benign and malignant lesions. Following this value, the statistical data on SWE showed a sensitivity of $97 \%$ (BI-RADS descriptors $87 \%$ ), a specificity of $83 \%$ (BI-RADS descriptors $78 \%$ ), a ppv of $88 \%$ (BI-RADS descriptors $84 \%$ ), an npv of $95 \%$ (BIRADS descriptors $82 \%$ ), and an accuracy of $91 \%$ (BI-RADS descriptors $83 \%$ ).

According to the wide range of US modalities discussed above, a time-saving diagnostic algorithm for an effective use of advanced 2D and 3D/4D US technologies was published by Weismann and Datz [43]. This algorithm has to be adapted to modern US elastography technology and follows the logical order of 8 different steps. 4D US is no longer included in this updated algorithm. These modified 8 steps are presented in table 1 .

\section{Conclusions}

Modern 2D B-mode imaging is used as the basic US technique to detect and describe breast lesions. 3D US is a perfect tool to analyze the grey-scale characteristics (BI-RADS descriptors) of a lesion, to measure the longitudinal axes perpendicular to each other and to calculate the volume of a lesion, to study the coronal plane and to document the lesion and the surrounding breast tissue. Complementary elastography displays the mechanical tissue properties and has the potential to enhance US specificity with maintained high US sensitivity. With all described elastography techniques, an overlap between benign and malignant lesions exists. Neither 4D grey-scale imaging nor 4D-VCI elastography have proven to enhance the true-positive or to reduce the false-positive results. As a consequence of this, 4D currently does not play a role in routine breast lesion assessment.

Summing up the discussion above, the answer to the question of this paper is: Elastography, especially on the highest standardized level with quantification of the tissue stiffness, is an important adjunct to 2D and 3D sonography. Elastography is not a stand-alone tool and does not replace $2 \mathrm{D}$ and $3 \mathrm{D}$ sonography.

\section{Acknowledgements}

C.M., H.E. and A.A. contributed literature research results to the publication and proof-read the manuscript.

\section{Disclosure Statement}

The author and the coauthors declare that there are no conflicts of interest.

\section{References}

1 Rizzatto G: Towards a more sophisticated use of breast ultrasound. Eur Radiol 2001;11:2425-2435.

2 Weismann CF: Breast ultrasound: new frontiers in imaging? Ultrasound Obstet Gynecol 2000;15:279281.

3 American College of Radiology: Illustrated Breast Imaging Reporting and Data System (BI-RADS) Ultrasound, ed 1. Reston, American College of Radiology, 2003.
4 Madjar H, Ohlinger R, Mundinger A, Watermann D, Frenz JP, Bader W, Schulz-Wendtland R, Degenhardt F: BI-RADS-analogue DEGUM criteria for findings in breast ultrasound - consensus of the DEGUM committee on breast ultrasound. Ultraschall Med 2006;27:374-379.
Cilotti A, Bagnolesi B, Moretti M, Gibilisci G, Bulleri A, Macaluso AM, Bartolozzi C: Comparison of the diagnostic performance of high-frequency US as a first- or second line diagnostic tool in non-palpable lesions of the breast. Eur Radiol 1997;7:1240-1244.

6 Kolb TM, Lichy J, Newhouse JH: Comparison of the performance of screening mammography, physical examination and breast US and evaluation of factors that influence them: an analysis of 27,825 patient evaluations. Radiology 2002;225:165-175. 
7 Buchberger W, Niehoff A, Obrist P, DeKoekkoekDoll P, Dunser M: Clinically and mammographically occult breast lesions: detection and classification with high-resolution sonography. Semin Ultrasound CT MR 2000;21:325-336.

8 Leconte I, Feger C, Galant C, Berliere M, Vande Berg B, D'Hoore W, Maldague B: Mammography and subsequent whole-breast sonography of nonpalpable breast cancers: the importance of radiologic breast density. AJR Am J Roentgenol 2003; $180: 1675-1679$.

9 Moon WK, Noh D-Y, Im J-G: Multifocal, multicentric, and contralateral breast cancers: bilateral whole-breast US in the preoperative evaluation of patients. Radiology 2002;224:569-576.

10 Cha JH, Moon WK, Cho N, Kim MS, Park HS, Han BK, Choe YH, Park JM, Im JG: Characterization of benign and malignant solid breast masses: comparison of conventional US and tissue harmonic imaging. Radiology 2007;242:63-69.

11 Weismann C, Hergan K: Current status of 3D/4D volume ultrasound of the breast. Ultraschall Med 2007;28:273-282.

12 Weismann CF: Recent advances in multidimensional 3D/4D breast imaging; in Ueno E, Shiina T, Kubota M, Sawai K (eds): Research and Development in Breast Ultrasound. Tokyo, Springer, 2005, pp 146-150.

13 Weismann CF: Multidimensional breast ultrasound: technical aspects and diagnostic applications. Ultraschall Med 2004;5:390-392.

14 Weismann CF: Three-dimensional sonography of the breast; in Kurjak A, Kupesic S (eds): Clinical Application of 3D Sonography, Vol 24. New York, London, Parthenon Publishing, 2000, pp 215-228.

15 Weismann CF: Ultra-som tridimensional da mama; in Montenegro CAB, Rezende Filho J, Almeida Lima ML (eds): Ultra-som tridimensional Atlas Comentado, Vol 6. Rio de Janeiro, Editora Guanabara Koogan S.A., 2001, pp 151-172.

-16 Scherzer O, Schoisswohl A: A fast and robust algorithm for $2 \mathrm{D} / 3 \mathrm{D}$ panorama ultrasound. RealTime Imaging 2002;8:53-60.

17 Weismann CF: Overview of new ultrasound technology and its application in breast imaging. EJC Suppl 2006;4:33-34.

18 Moon WK, Chang RF, Chen CJ, Chen DR, Chen WL: Solid breast masses: classification with computer-aided analysis of continuous US images obtained with probe compression. Radiology 2005;236:458-464.
19 Itoh A, Ueno E, Tohno E, Kamma H, Takahashi H, Shiina T, Yamakawa M, Matsumura T: Breast disease: clinical application of US elastography for diagnosis. Radiology 2006;239:341-350.

20 Bercoff J, Chaffai S, Tanter M, et al.: In vivo breast tumor detection using transient elastography. Ultrasound Med Biol 2003;29:1387-1396.

21 Tanter M, Bercoff J, Athanasiou A, et al.: Quantitative assessment of breast lesion viscoelasticity: inital clinical results using supersonic shear imaging. Ultrasound Med Biol 2008;34:1373-1386.

22 Athanasiou A, Tardivon A, Tanter M, et al.: Breast lesions: quantitative elastography with supersonic shear imaging - preliminary results. Radiology 2010;256:297-303.

23 Weismann CF: Role of colour Doppler ultrasound in breast imaging. EJC Suppl 2006;4:41-42.

24 Huber S, Delorme S, Knopp MV, et al.: Breast tumors: computer-assisted quantitative assessment with colour Doppler US. Radiology 1994;192:797801.

25 Delorme S, Anton HW, Knopp MV, et al.: Breast cancer: assessment of vascularity by colour Doppler. Eur Radiol 1993;3:253-257.

26 Kedar RP, Cosgrove D, McCready VR, et al.: Microbubble contrast agent for colour Doppler US: effect on breast masses. Radiology 1996; 198:679-686.

27 Huber S, Helbich T, Kettenbach J, Dock W, Zuna I, Delorme S: Effects of a microbubble contrast agent on breast tumors: computer-assisted quantitative assessment with color Doppler US - early experience. Radiology 1998;208:485-489.

28 Stuhrmann M, Aronius R, Roefke C, Schietzel M: Vaskularisation von Mammatumoren: Einsatz des Ultraschallkontrastmittels in der Dignitätsbeurteilung. Vorläufige Ergebnisse. Fortschr Röntgenstr 1998;169:360-364.

-29 Madjar H, Jellins J: Role of echo enhanced ultrasound in breast mass investigations. Eur J Ultrasound 1997;5:65-75.

30 Hatzung G, Grunwald S, Zygmunt M, et al.: Sonoelastography in the diagnosis of malignant and benign breast lesions: initial clinical experiences. Ultraschall Med 2010;31:596-603.

31 Stavros TA, Thickman D, Rapp CL, Dennis MA, Parker SH, Sisney GA: Solid breast nodules: use of sonography to distinguish between benign and malignant lesions. Radiology 1995;196:123-134.

32 Rahbar G, Sie AC, Hansen GC, et al.: Benign versus malignant solid breast masses: US differentiation. Radiology 1999;213:889-894.
33 Teubner J, Bohrer M, van Kaick G, et al.: Correlation between histopathology and echomorphology in breast cancer; in Madjar H, Teubner J, Hackelöer B-J (eds): Breast Ultrasound Update. Basel, Karger, 1994, pp 63-74.

34 Cho N, Moon WK, Cha JH, Kim SM, Han BK, Kim EK, Kim MH, Chung SY, Choi HY, Im JG: Differentiating benign from malignant solid breast masses: comparison of two-dimensional and threedimensional US. Radiology 2006;240:26-32.

35 Graf O, Helbich TH, Fuchsjaeger MH, et al.: Follow-up of palpable circumscribed noncalcified solid breast masses at mammography and US: can biopsy be averted? Radiology 2004;233:850-856.

\$36 Graf O, Helbich TH, Fuchsjaeger MH, et al.: Ultrasound follow-up of palpable solid probably benign breast lesions (BI-RADS category 3 ). RöFo 2004:176:1251-1256.

37 Hong AS, Rosen EL, Soo MS, Baker JA: BIRADS for sonography: Positive and negative predictive values of sonographic features. AJR Am J Roentgenol 2005;24:161-167.

38 Lazarus E, Mainiero MB, Schepps B, et al.: BIRADS lexicon for US and mammography: interobserver variability and positive predictive value. Radiology 2006;239:385-391.

39 Baker JA, Kornguth PJ, Scott Soo M, Walsh R, Mengoni P: Sonography of solid breast lesions: observer variability of lesion description and assessment. AJR Am J Roentgenol 1999;172:16211625.

40 Rotten D, Levaillant J-M, Zerat L: Analysis of normal breast tissue and of solid breast masses using three-dimensional ultrasound mammography. Ultrasound Obstet Gynecol 1999;14:114-124.

41 Rotten D, Levaillant J-M, Zerat L: Use of threedimensional ultrasound mammography to analyze normal breast tissue and solid breast masses; in Merz E (ed): 3-D Ultrasonography in Obstetrics and Gynecology. Philadelphia, Lippincott, Willams and Wilkins, 1998, pp 73-78.

42 Burnside ES, Hall TJ, Sommer AM, et al.: Differentiating benign from malignant solid breast masses with US strain imaging. Radiology 2007; 245:401-410.

43 Weismann CF, Datz L: Diagnostic algorithm: how to make use of $2 \mathrm{D}, 3 \mathrm{D}$ and $4 \mathrm{D}$ ultrasound technologies in breast imaging. EJR 2007;64:250 257. 